\title{
MERMAIDS, MERCULTURES AND THE AQUAPELAGIC IMAGINARY
}

\author{
[Received July 8th 2018; accepted September 8th 2018 - DOI: 10.21463/shima.12.2.03] \\ Philip Hayward \\ University of Technology Sydney and Southern Cross University (Australia) \\ <prhshima@gmail.com>
}

\begin{abstract}
Critical-analytical studies of mermaids, mermen and similar figures, and the associated cultural practices and phenomena that can be characterised as constituting broader "mercultures," have burgeoned over the last five years. This critical attention has been long overdue as mermaids (in particular) have had a continuing presence in Western culture since the late Medieval period and have been strikingly prominent in international popular culture since the 1980s. Recent books have addressed themes such as the representation of mermaids and the production of knowledge in 16th and 17th Century England (Pedersen, 2016), popular cultural "fan phenomena" concerning mermaids (Guitton [ed], 2018) and the history of mermaids' and mermen's representation in Western audiovisual media (Hayward, 2017). A significant body of work is also emerging on the manner in which the mermaid has been adapted into non-western cultures (Fraser, 2017; Hayward [ed], 2018). This increase in scholarly activity led to the organisation of an international conference entitled 'Mermaids, Maritime Folklore and Modernity' held at the Kulturhuset Indre By in Copenhagen in October 2017. Several of the articles featured in this special issue of Shima are expansions of papers delivered at that event, ${ }^{1}$ complemented by a number written in response to the journal's call for submissions for this theme issue.
\end{abstract}

Over the last five years Shima has widened the focus of its initial address to island cultures to consider various aspects of islands and coastlines and their interactions with maritime environments. One prominent concept explored by various contributors to the journal has been that of the aquapelago, an assemblage of terrestrial and aquatic spaces generated by human livelihood activities. ${ }^{2}$ Recent articles such as Suwa $(2016,2018)$ have begun to explore the cultural implications of the aquapelago as an entity constituted by human activity (at certain times, in certain places) that have subsequently been inscribed within individual and social consciousness, memory and material and immaterial culture. Outside of Shima, I have proposed the concept of there being what might be termed an "aquapelagic imaginary" arising from such processes. I first advanced this concept in the introduction to my 2016 book Making a Splash: Representations of Mermaids (and Mermen) in 2oth and early 21st Century Audiovisual Media. The premise of that introduction was that the mermaids (and mermen) present in contemporary western popular culture could be traced back to some European coastal communities' pre-modern engagements with their aquapelagic locales. In their original context, at least, such figures can be understood to have reflected and transcended perceptions of the limits of human presence in and experience of aquatic

\footnotetext{
${ }^{1}$ Galman, Goggin, Inkol, Jilkén, Tran and Wasilewski \& Kostrzewa.

${ }^{2}$ See the collection of articles on the topic featured on the Shima journal website: http://shimajournal.org/anthologies.php
}

Shima <www.shimajournal.org> ISSN: 1834-6057 
spaces. Through such processes it is possible to assert that an "aquapelagic imaginary" came into being and manifested itself as an aggregation of beliefs and imagined figures. We can see similar aspects in a variety of contemporary Pacific Island cultures, such as those of the Torres Strait Islands, ${ }^{3}$ and in areas such as Chiloé, where elements of aquapelagic folklore have persisted despite the diminishing aquapelagic status of the regional community. In the case of the latter, the aquatic humanoids that resulted from the mestizaje (mixing) of indigenous and Spanish colonial beliefs and mythology maintain a strong presence in both traditional folklore and in modern deployments of it for artistic and/or political purposes (see Garrido, Bendrups and Hayward [forthcoming, 2019] for detailed discussion).

In his contribution to this issue, Suwa (2018) provides a valuable elaboration of the manner and means by which a lacustrine-aquapelagic imaginary has operated in and around Japan's Biwako (Lake Biwa) from medieval times through the treatment (and related construction) of particular beliefs, spaces, places and networks as sacred. His subtle essay examines the manner in which networks of agency and affect drew on and reflected the region's aquapelagic imaginary through sacred artefacts and sites. As he identifies, folkloric stories concerning the ningyo - a creature with a fish's body, a human head and human-like intelligence - were central to and emblematic of inscriptions of an aquapelagic sensibility around the lake. But, as he elaborates, the ningyo were not only a motif in oral folklore, they also materialised in the form of ningyo no miira - fabricated artefacts (usually comprising fish's bodies and the upper torsos of monkeys) that were represented (and/or traded) as (actual) mummified ningyo. Several examples of these were acquired by Japanese religious orders in the 1700 s and 1800 s and were retained and presented as preserved ningyo corpses. The problematic materiality of these artefacts (presented as actual creatures) was further compounded by their predominant retention in closed and/or sealed containers. Whatever their origins, and whatever their actual nature as manufactured approximations of ningyo form, they represented denizens of an aquapelagic realm incorporated into dominant religious cosmologies and institutions. Their occlusion, far from undermining their sacred status, was key to it, enhancing their mystique and sacredness.

This discussion is not only pertinent for the case of Biwako, and of Japan more generally. The materialisation of the folkloric figure of the ningyo via manufactured artefacts in Japan overlapped with related promotions of the mermaid in secular contexts in the West in the 19th Century. Despite using similar artefacts, the process of Japanese sanctification of ningyo no miira was diametrically the reverse of P.T Barnum's famous exhibition of one ${ }^{4}$ as the preserved body of a mermaid in the 1840 os at his 'American Museum' in Manhattan. ${ }^{5}$ Whereas the ningyo no miira artefacts preserved around Biwako were deployed and presented in a spiritual-semiotic context that simultaneously hid them and gave them resonant meaning; Barnum's re-presentation of a ningyo no miira as something other than what it was (ie a fabricated approximation of a ningyo) and as what it clearly was not - ie a preserved mermaid corpse - required different semiotic strategies to maintain this conceit. In Barnum's case, it was a technique no less blatant - although somewhat less subtle - than the boxed-in reliquaries of Japanese sacred sites. This involved advertising the ningyo no miira he had purchased as the preserved corpse of a mermaid (supposedly from "Feejee" [ie

\footnotetext{
3 See, for instance, McNiven and Feldman (2003) for discussion.

${ }^{4}$ While there is no conclusive evidence that the artefact acquired by Barnum was manufactured in Japan; its appearance was closely similar to ones manufactured and retailed in Japan in the early-mid 1800 . (NB the artefact is not available for scrutiny as it was destroyed in a fire in 1865).

${ }^{5}$ See Bondeson (1999: 36-63) for an extended discussion of the background and high-profile exhibition of the specific ningyo no miira in Western Europe and the USA.
}

\author{
Shima Volume 12 Number 22018
}


Fiji]) and promoting the exhibit with posters of a glamourous mermaid (despite the severe mismatch between the shrivelled exhibit and the poster figure). ${ }^{6}$ Whereas the appropriation and misrepresentation of ningyo no miira artefacts in Japan by religious groups relied upon the activation of a deep-seated aquapelagic sensibility; Barnum's exhibition was more cynical and opportunistic. While it may have reflected a continuing fascination for the sea and remote tropical islands in the cities it was exhibited in, it did not operate within a community as deeply imbued with an aquapelagic sensibility and imaginary as that around Biwako. Instead the potency of the mermaid (clearly apparent in the former's ability to attract large crowds to see an artefact that bore minimal resemblance to her form) can be asserted to have resulted from the pleasing and potent polyvalence that is discussed below.

The above discussion acknowledges the emergence and sustained presence of aquatic humanoid figures in pre-Modern and/or transitional cultures but the representation of such folkloric elements in 19th-21st Century cultural media has to be understood within a different frame. Few contemporary Western societies have implication with aquapelagic assemblages comparable to those that operated in a number of island and coastal locations in pre-Medieval and Medieval Europe and/or in various non-Western locations. Instead of such a direct and organic connection, it can be argued that the persistence of elements of maritime folkloric heritage, such as the mermaid, in the contemporary world results from their symbolic polyvalence. Reflecting on Andersen's seminal short story 'Den lille Havfrue' ('The Little Mermaid'), Easterlin has characterised the manner in which, "mermaids and her kinfolk evoke a shifting constellation of concerns, not a fixed set of meanings" (2001: 256). With specific regard to the mermaid's representation in western audiovisual media, I have previously drawn on Freudian discourse to argue that the polyvalent sexual-symbolic signification of the mermaid's form and, especially, her tail (the very root of her difference and, thereby power), have ensured her longevity and prominence in popular culture (Hayward, 2017). My book-length study identified that the fish-tailed mermaid is visually and associatively given a variety of phallic powers in Western audio-visual media fictions that make her a type of "supercharged" femme fatale whose charismatic agency frequently "overflows" the various narrative fates assigned to her (ibid: 12-15). As seductress and/or villainess, where men are concerned, and, variously, as a sister-figure and/or inspiration to human females; the mermaid of 2oth and 21st Century video, television and cinema breaksopen stereotypes and freely exercises a variety of powers seldom available to her human counterparts. Related to these discussions, I have argued that it is precisely the reverse namely the merman's awkward relation to that polyvalence, and the more generally phallocentric nature of Western culture - that explains his low prominence during much of the 2oth Century (ibid: 151-166, also see Hayward and Milner, 2018).

The merman's awkward relation to phallocentric orders, human society more broadly and the beguiling, slippery vibrancy of the mermaid as she swims through the former, are made apparent in Clara Guernsey's novel The Merman and the Figurehead (1871), analysed by Mitchell in this issue. While Guernsey represents a peaceful and charmingly eccentric merworld beneath the sea that parodies many aspects of 19th American Century "polite society," the book represents its central figure as an obstinate and dull-witted individual who develops a powerful attraction to a wooden mermaid figurehead that persists until it falls on him and kills him. As Mitchell relates, the merman and his fixation provide a parodic mirror for a terrestrial male's attraction to a (figuratively) "wooden" female who he marries. Effectively locked in the functionality of reflecting aspects of terrestrial characterisations,

${ }^{6}$ With the difference in appearance - presumably - being construed to have resulted from processes of mummification. 
the novel's merman possesses no "alchemical" power akin to that Inkol and Woodcock ascribe to the mermaid - an aspect made all the more apparent when he is confronted by the vision of a naked, shimmering Nereid whose libidinous charisma fails to rouse him from his stuporous attachment to a wooden object (Guernsey, 1871: 97).

Popular cultural engagements with mer-themes are however highly fluid, and one of the most notable aspects of the latter over the last decade has been a resurgence of mermen in various contexts. This issue of Shima includes two articles on such phenomena that show how the merman is currently being reconsidered in ways that reflect and/or negotiate his phallic lack (Hayward and Thorne, 2018 and Jilkén, 2018). Hayward and Thorne examine the manner in which the figure of the merman has recently been adopted and promulgated by a group of hirsute and predominantly large bodied males in Newfoundland. This activity, initiated by a themed calendar project, has led to active reflection on what masculinity means in a post-aquapelagic island culture where established male roles and stereotypes are in transition in synchrony with livelihood activities. In this context, the merman has been both embraced and significantly localised, the latter aspect being most evident in the coining of a new term in Newfoundland English ${ }^{7}-$ the merb'y - to refer to him. As the article details, the calendar's images - and the considerable affective engagement with them by local and international audiences - have served to "re-masculinise" the merman (within traditional gender roles and stereotypes) through having archetypally masculine men engaging in the role-play and through having the images presented as role-play rather than as realist-fantasies of a type more common to fiction cinema. Jilkén (2018) takes another perspective, examining a group of online visual illustrations of mermen targeted at gay audiences on Internet platforms such as DeviantArt. In contrast to types of merb'y images produced in Newfoundland, which conform to traditional versions of the merman as fully fishtailed from the waist down, Jilkén examines a range of images in which mermen's tails are rendered with musculature and curves that effectively represent them as having buttocks. Rather than focus on the absence of genitals from the front of the mermen's tails, Jilkén asserts that the mermen in the works he analyses present an alternative to gender binaries, since:

the merman's frequently exposed bottom... suggests that a male body is just as penetrable as a female's. In these modern illustrations of the merman the fishtail does not castrate the merman or make him impenetrable. (2018: 205)

These analyses (and similar reinterpretations of other mermale entities, such as the amphibious male protagonist of Guillermo del Torro's film The Shape of Water [2017]), point to an active contemporary engagement with the potential of mermales (of various types) as a counter-balance to the prominence of the mermaid in contemporary global culture.

Many of the articles in this volume either explore the specific constitution of mermaids, mermen, Melusine and/or fully human formed aquatic humanoids (such as Nereids and [some] sirens) within a range of modern cultural practices or else approach these en masse using various theoretical paradigms. Young provides a detailed account of the last reported mermaid sighting to have been given wide (and largely unsceptical) coverage in the British media, in the early 1800 , identifying the processes of memory, reflection, representation and discussion that accrued around a single incident at a time of growing scientific

\footnotetext{
${ }^{7}$ Newfoundland English is rich with words not in circulation in standard Canadian-English, many of which derive from regional and/or archaic English and Irish-English terms.

${ }^{8}$ One of the examples Jilkén discusses also represents a merman with very visible erection.
}

\section{Shima Volume 12 Number 22018}


rationalism. Complementing this with regard to the late 2oth and early 21st centuries, Goggin provides a wide-ranging reflection on aspects of rhetoric and epistemology in addressing the question as to how we might understand mermaids to be "real." Sustained discussion leads him to the conclusion that:

mermaids themselves are ontological as discursive co-constituents in the making and unmaking of relationships and knowledge in confluences and experiences of science, mythology, legend, and popular culture. (2018: 21)

Approaching the topic from very different conceptual and theoretical viewpoints, Inkol's contribution to this issue provides a significant intervention into recent debates about the broader significance and interpretation of mer-culture by asserting the mermaid's origins in and agency-empowerment through what might be considered as the "oceanic unconscious" of both the individual and of society in general. Drawing on Jung, and his characterisation of the mermaid as a particularly prominent form of the female anima, ${ }^{9}$ she asserts that:

the mermaid can be interpreted as the vehicle for the transformation engendered by navigating the personal unconscious, leading to a vaster sea: she is the psychopomp that ferries the human from neurosis to integration, and ultimately leads onto a new realm of meaning, the collective unconscious. The mermaid can be understood as the figure that navigates the mirroring, watery maze of the personal unconscious, overcoming the obstacles and relays posed by the shadow and the other indwelling archetypes of the personal unconscious; in this sense, the process of navigating and deciphering the maze of the personal unconscious can be understood as a process of becoming-mermaid: to emerge from the traps and challenges of the personal unconscious, fins are required to swim through its dark, reflective waters. (2018: 57)

This characterisation is apposite for consideration of the concept of the aquapelagic imaginary. In particular, it points to the manner in which the latter might be implicated (in variously generative, reflective or complementary manners) with the fluid realm of the subconscious envisaged by Jung and characterised by Inkol above. In both, the mermaid appears as a figure that negotiates the limits and contradictions of human subjectivity and consciousness freed from the restraints of everyday environmental-material existence.

In one of the more audacious aspects of her article, Inkol takes the mermaid anima she has asserted as a figure of the oceanic unconscious identified by Jung and - retaining the characterisations she attributed to her in a fluid realm - places her (whole, swimming and vibrant) in the topographic realm of the collective unconscious posed by Deleuze and Guattari. In this she swims through a matrix upon the ebbs and flows of desire and of the "desiring machine" that Deleuze and Guattari posit as the "motivating force at work in the world":

Desire is a machine: a desiring-machine, the structural formation of the collective unconscious, its network of flows, the metal skeleton that underlies the material world (Deleuze and Guattari, 1983). Desiring-machines move like keys that open and close domains, instituting and rupturing connections that previously existed, dictating the course of movement of the flow of desire, its

\footnotetext{
${ }^{9}$ See Hayward and Thorne (2018: 208, 211) for discussion of the term, its origins and meaning.
}

\section{Shima Volume 12 Number 22018}


ingress and egress between things. Desire as force and structure, is constantly shifting, reforming itself through its connections and disruptions of connection, creating circuits of energy (Deleuze and Guattari, 1987: 334). (Inkol, 2018: 6-)

Imbued with Jungian qualities retained in her transition between concept-worlds, Inkol perceives and characterises the mermaid as embodying key aspects of desire as a machinic system that flows to such an extent that she contends that:

Deleuze and Guattari's machinic unconscious can be envisaged as a mermaidmatrix, its flows of transport a metallic finned structure, the unconscious architecture of the machinic mermaid. A moving nexus of mermaid-tails that formulate a web or maze, a mermaid-rhizome-machine (ibid: 62).

Returning to the type of considerations raised by Goggin, Inkol summarises the overall project of her article as being "grounded in experimental praxis" and as employing the mermaid as "an axle to orient epistemological inquiry" (ibid: 63). She further contends that figures such as the mermaid "can be employed as a mode of thinking to glean epistemological insight" and that figures such as the mermaid can be conceived of as "forms of thought... crystallised as form, not superfluous, merely decorative or superficial, but emblems of meaning, encoded within a larger structure of meaning" that can lead to the "realm of understanding" (ibid: 52-52).

In seeking to understand the appeal of Melusine to the Surrealist poet André Breton, Woodcock draws on Deleuze (1989) to propose a "fixed-explosive" loosening of images, associations and, indeed, senses of time in order to understand the present:

better as a dynamic interpenetration of pasts and futures, or as a perpetual collision and intermingling of the actual (the present moment) and the virtual (a memory or the idea of an object, for example). (2018: 45)

Woodcock's article outlines the complex signification (and changing form of) Melusine, a legendary Medieval draconopede who has subsequently been represented as either a winged and/or dual-tailed mermaid. ${ }^{10}$ After detailing historical changes in her form, he contends that Melusine is an example of what Deleuze referred to as a "crystal image" that disrupts determinist etymology (1989: 79) by being "always on the verge of actualising itself" (2018: 46). Through his discussion, Woodcock demonstrates the potency of her form and the symbolic "charge" that inspired Breton to author his mystical work Arcane 17 (2008).

A group of articles in this issue address the representation of sirens, nereids, nymphs and mermaids (and transitions between these) in the work of various 19th-21st Century Western European painters (specifically, Böcklin, Lalyre, Waterhouse and Guenot). These articles explore the strong symbolic potency of the mermaid elaborated by Inkol above and their discussions involve considerations of the manner in which female form is developed with regard to established mythologies and then deployed in manners that reflect both a range of contemporary contexts and trends within individual artists' oeuvres. Tran documents what she refers to as a "paradigm shift" in Böcklin's work and the manner in which sustained consideration of the Nereid and the potential for her to be fully integrated with an oceanic

${ }^{10}$ The later image being perpetuated by the ubiquitous Starbucks' logo, early versions of which showed the figure holding her split tail apart, before revisions to the logo zoomed-in on the central figure. 
environment resulted in his transforming her from a (human-form) "figure in the pictorial space" to that of a fish-failed female entity who "embodied in her sensual shape and expression the drawing power of the sea [and] the vertiginous suggestion of its abysmal depths" (2018: 163) in a manner that ultimately resulted in her being defined "chiefly through her liberated eros, unyoked and unbeholden to any power but her own" (ibid: 101). By contrast, Butkus, Fleury and Raoulx relate that Lalyre's sirens, imagined and represented in the waters around Carteret (in south-western Normandy) and in various mythical tableaux, remained resolutely human-formed despite being represented in close association with the libidinal surge of the waves and recurrent monstrous fish intent on intertwining with them. Lalyre's representations stopped short of affecting the physical transformation Böcklin moved towards over an extended duration and remained arrested at the point of Lalyre's imagination of women as figures of desire displaced from terrestrial existence and behavioural norms and suspended at the edge of the sea, close to "abysmal depths" along the shore variously desired by painters and tourists alike in 18th Century France. ${ }^{11}$ Luta's study, by contrast, focusses on a single image by Waterhouse, 'Hylas and the Nymphs' (1896) and a recent debate about the political aspects of its representation of young, bare-breasted women occasioned by its temporary removal from exhibition at Manchester Art Gallery in 2018. The figures in the Waterhouse's painting are ambiguous as to their lower bodies, ${ }^{12}$ which remain below the surface of a lily-covered pool as the nymphs attempt to draw a young man into the water and their embraces. While the pool represented in the painting is apparently shallow; it, and the nymphs who crowd it, evoke spaces as profoundly aquatic and as deeply "other" as the "abysmal depths" suggested by Böcklin's paintings. Luta characterises the pool and the nymphs who crowd it as offering a "desirable" realm for Hylas (and, implicitly, men in general) where "seduction and submersion" are combined (2018: 131).

Similar themes to those of Böcklin, Lalyre and Waterhouse are deployed - very differently in Guenot's 2018 artwork 'Brexit Wrexit.' In her illuminated cartographic tableau, Guenot uses the figure of the fish-tailed siren to symbolise the simultaneous threat and lure of the European Community to resistant "little Englanders"13 who are seeking "Brexit" (ie Britain's exit from the European Union). As Guenot describes in her extended artist's note in this issue, she represents the embattled and resistant inflexibility of "Brexiters" in the form of the compound lionship figure historically associated with England's Cinque Ports through its coat-of-arms. ${ }^{14}$ The (literal) woodenness and inflexibility of the heraldic figure's hindparts is telling. This aspect renders the figure (liberated from its role as a heraldic motif and set upon the seas) as a mismatched combatant in a pictorial space representing the English Channel as a battleground between two types of aquapelagic figures, the smoothly proficient fish-tailed siren, as adept and at-home upon or beneath the waters and on-shore; and the lionship entity, whose design confines it to the surface of the waves.

Similar to Guenot's reflection, Wasilewski and Kostrzewa examine the deployment of the Syrenka, the heraldic image of Warsaw - a fishtailed siren brandishing a shield and sword as a tattoo motif on the flesh of residents of the city. Providing a background to the development of the figure in its current form, the authors analyse the variety of forms the

\footnotetext{
${ }^{11}$ See Corbin (1994), from which Butkus, Fleury and Raoulx take their article's title.

${ }^{12}$ NB Waterhouse is also known for his 1900 painting 'The Mermaid,' which has been widely reproduced.

${ }^{13}$ I'm aware that the majority of Welsh voters and some Scottish voters supported Brexit but the primary impetus for the 'Leave' campaign was the largely English-based UKIP party and much of its rhetoric reflected traditional 'Little Englander' views.

${ }^{14}$ See Guenot (2018: 136-137) for discussion.
} 
figure now takes and the motivations Varsovarians have for adopting it (ranging from personal identification with aspects of the figure through a desire to clearly align themselves with the city and the civic values they perceive it to embody). Galman's study of the use of mermaid images in self-portraits by transgender children traverses similar issues of identification and personal significance in identifying the role that mermaid images play in giving insights into the perceptions of young transgender individuals. Drawing on Pedersen's work on aspects of the mermaid as a figure in the late $15^{\text {th }}$ to early 16 th centuries, Galman contends that:

Then, as now, the mermaid stood for a challenge or disruption to the existing order and to categorisation systems in the existing schema of religious and folk belief. This extended to understandings of sex and gender, where the mermaid can be seen as an early symbol of hybridity, challenge and contradiction. (2018: 168)

Developing this theme in her analysis of transgender children's artworks, she contends that (for this group, at least), the mermaid may represent:

not just a symbolic cultural broker in any of these senses, but also a tangible metaphor for transgirls who move between transgender and cisgender worlds while simultaneously occupying a liminal position in their daily realities as girls who are more-than-girls. In short, it is one thing to move between cultures, and quite another to live in-between as a constant border-crosser, and to do so with pride. The children in this study... are proud of who they are and keen to find representation of what it feels like to be in joyful, prideful, liminality. (2018: 175)

A similar, although less intense sense of joy and pride in exploring liminality and in "trying on" the apparel and appearance of a mermaid (through prosthetic tails and related stylings) is evident amongst the role-playing tourists discussed by Porter and Lück in their case study of a mermaid "school" in Boracay island in the Philippines in 2017. As a phenomenon, merthemed tourism, its intersection with oceanic-environmental awareness and its promise of temporary aquapelagic "othering" represents a fertile field for future inquiry and analysis.

Overall, the varied and insightful articles collected in this issue underline the richly nuanced set of associations and deep symbolic aspects of mermaids, mermen and broader mercultures in modern contexts far removed from the aquapelagic societies whose livelihood activities resulted in a sustained imaginative engagement and identification with liminal terrestrial-aquatic locales. As Pedersen notes in her concluding research note to this volume, the mermaid continues to be a valuable figure "to think with" (2018: 250), possessing significant "epistemic value" (ibid) in its own right that also "highlight[s] how cultural knowledge is produced" (ibid). There can be no greater confirmation of the richness and multiple polyvalence of mermaids and similar figures that this theme issue of Shima (and the aforementioned books on the topic) only begin to illuminate the mysteries of their depths and the fractal complexities of their symbolism for various artists, audiences, critics and scholars. "Thinking with" mermaids and their kin proves a singularly expansive activity.

Thanks to John Sutton for his comments on early notes for this Introduction and to Peter Goggin, Tara Pedersen and Alex Woodcock for their feedback on an initial draft.

\author{
Shima Volume 12 Number 22018
}

- 8 - 


\section{BIBLIOGRAPHY}

Bondeson, J (1999) The Feejee Mermaid and Other Essays in Natural and Unnatural History, Ithaca: Cornell University Press

Breton, A (2008) Arcane 17 (Béhar, H [ed]) Paris: Biro Éditeur

Butkus, C, Fleury, C and Raoulx, B (2018) 'Desiring the Shore: Adolphe Lalyre and the Sirens of Carteret', Shima v12 n2: 104-125

Deleuze, G (1989) Cinema II: The Time-Image (translated by Tomlinson, H and Gaketa, R), London: Athlone Press

Deleuze, G and Guattari, F (1983) AntiOedipus (translated by Massumi, B), Minneapolis: University of Minnesota Press

----- (1986) Kafka: Towards a Minor Literature (translated by Polan, D), Minneapolis: University of Minnesota Press

----- (1987) A Thousand Plateaus (translated by Massumi, B), Minneapolis: University of Minnesota Press

Corbin, A (1994) The lure of the sea: the discovery of the seaside in the western world, 17501840 (translated by Phelps, J) Berkeley: University of California Press

DeviantArt (nd): https://www.deviantart.com - accessed 28th August 2018

Easterlin, N (2001) 'Hans Christian Andersen's Fish out of Water', Philosophy and Literature v25 n2: 251-277

Fraser, L (2017) The Pleasures of Metamorphosis: Japanese and English Fairy Tale Transformations of "The Little Mermaid", Detroit: Wayne University Press

Campbell Galman, S (2018) 'Enchanted Selves: Transgender Children's use of mermaid imagery in self-portraiture', Shima v12 n2: 163-180

Garrido, W, Bendrups, D and Hayward, P (2019) Música de Chiloé: Folklore, Syncretism and Cultural Development in a Chilean Aquapelago, Lanham: Lexington Books

Goggin, G (2018) “'Are Mermaids Real?” Rhetorical Discourses and the Science of Merfolk', Shima v12 n2: 12-23

Guenot, L (2018) 'Lionships and Sirens: Deploying heraldic figures in critique of Brexit', Shima v12 n2: 135-143

Guitton, M.J (ed) (2016) Fan Phenomena: Mermaids, Bristol: Intellect Books

Hayward, P (2017) Making a Splash: Mermaids (and Mermen) in 2oth and early 21st Century Audiovisual Media, New Barnet: John Libbey and Co/Indiana University Press

Shima Volume 12 Number 22018 
----- (ed) (2018) Scaled for Success: The Internationalisation of the Mermaid, New Barnet: John Libbey and Co/Indiana University Press

Hayward, P and Milner, L (2018) 'Shoreline Revels: 'Perversity, Polyvalence and Exhibitionism at Coney Island's Mermaid Parade', in Hayward (ed) Scaled for Success: The Internationalisation of the Mermaid, New Barnet: John Libbey and Co/Indiana University Press: 209-226

Hayward, P and Thorne, C (2018) 'I's the Merb'y: Masculinity, Mermen and Contemporary Newfoundland', Shima v12 n2: 208-230

Inkol, C (2018) 'Melusine Machine: The Metal Mermaids of Jung, Deleuze and Guattari', Shima v12 n2: 52-65

Jilkén, O (2018) “'A Phallus out of Water" The construction of mer-masculinity in modern day illustrations', Shima v12 n2: 195-207

Luta, I (2018) 'J.W Waterhouse's “Hylas and the Nymphs”" Submerging a Fantasy', Shima v12 n2: 126-134

McNiven, I and Feldman, R (2003) 'Ritually Orchestrated Seascapes: Hunting Magic and Dugong Bone Mounds in Torres Strait, NE Australia', Cambridge Archaeological Journal v13 n2: 169-194

Mitchell, M (2018) “I'd like to be Under the Sea": Modelling gender in Clara F Guernsey's The Merman and the Figure-Head', Shima v12 n2: 181-194

Pedersen, T (2016) Mermaids and the Production of Knowledge in Early Modern England, Abingdon: Routledge

----- (2018) 'Thinking with Mermaids Here and Now', Shima v12 n2: 250-255

Porter, B.A and Lück, M (2018) 'Mermaiding as a form of Marine Devotion: A case study of a mermaid school in Boracay, Philippines,' Shima v12 n2: 231-249

Suwa, J (2017) 'Becoming Island: the Aquapelagic Assemblage of Benten-sai Festivals on Sakurajima, in Sai Village, Northern Japan', Shima v11 n2: 5-19

----- (2018) 'Ningyo Legends and the Animation of an Aquapelagic Assemblage around Biwako, Central Japan', Shima v12 n2: 66-81

Tran, H (2018) 'When the Nereid became Mermaid: Arnold Böcklin's Paradigm Shift', Shima v12 n2: 82-103

Wasilewski, J and Kostrewa, A (2018) 'Syrenka Tattoos: Personal Interpretations of Warsaw's Symbol', Shima v12 n2: 144-162

Woodcock, A (2018) 'Melusine as Alchemical Siren in Breton's Arcane 17' (1945) Shima v12 n2: $37-51$

\section{Shima Volume 12 Number 22018}

- 10 - 
Hayward: Mermaids, Mer-Cultures and the Aquapelagic Imaginary

Young, S (2018) 'The Reay Mermaids: In the Bay and in the Press', Shima v12 n2: 24-36

Shima Volume 12 Number 22018

- 11 - 